\title{
Salvage HIFU for biopsy confirmed local prostate cancer recurrence after radical prostatectomy and radiation therapy: Case report and literature review
}

\author{
Rebekah Rittberg, MD;* Tadeusz Kroczak, MD; Neil Fleshner, MD, FRCSC;; Darrel Drachenberg, MD, FRCSC*
}

"Section of Urology, Department of Surgery, University of Manitoba, Winnipeg, MB; *Section of Urology, Princess Margaret Hospital, University Health Network, University of Toronto, Toronto, ON

Cite as: Can Urol Assoc J 2015;9(9-10):E671-2. http://dx.doi.org/10.5489/cuaj.2888 Published online September 9, 2015.

\section{Abstract}

High-intensity focused ultrasound (HIFU) is a treatment option for low- and intermediate-risk prostate cancer and more recently has been used as salvage therapy after failed radiation therapy. We present a case of local recurrence with biochemical failure after radical prostatectomy and salvage external beam radiation therapy with salvage HIFU without biochemical recurrence at 20 months.

\section{Introduction}

Prostate cancer is the most common cancer in Canadian men. ${ }^{1}$ Although most men are diagnosed and treated early, many still have biochemical recurrence requiring salvage therapy. Traditionally in radical prostatectomy (RP) patients, biochemical failure after salvage radiation is managed with androgen deprivation therapy (ADT) to slow disease progression. We present a case of biochemical failure after RP and then subsequent biochemical failure after salvage radiation managed with salvage HIFU on biopsy confirmed prostate cancer.

\section{Case report}

A 72-year-old man presented with an elevated prostatespecific antigen (PSA) of 5.98 and a 2-cm nodule identified on digital rectal examination (DRE) in the prostatic fossa. Eleven years prior, he underwent a RP with bilateral pelvic lymph node dissection which reveled pT2cN0Mx Gleason $3+4=7$ prostate adenocarcinoma with positive margins at the apex and posterior prostate. Immediate biochemical failure with a PSA of $1.0 \mathrm{ng} / \mathrm{mL}$ postoperatively was treated with salvage external beam radiation therapy (EBRT) to the prostate bed about 12 months after surgery with 6400 cGy over 32 fractions. PSA nadired at $<0.1 \mathrm{ng} / \mathrm{mL}$; however, it began to rise with a doubling time of less than 12 months. PSA rose to 5.98 at which time a palpable $2-\mathrm{cm}$ nodule was noted on DRE.

Transrectal ultrasound guided biopsy of the nodule revealed Gleason $4+4=8$ prostate adenocarcinoma in $4 / 4$ cores. Metastatic workup was negative. ADT was administered for 12 months. Due to the small volume of tissue, cryotherapy was not an option. Minimal prostate calcifications and favourable distance and geometry between the anterior prostate tissue and rectal wall allowed for salvage HIFU. Salvage HIFU was performed and PSA continues to be undetectable 20 months after treatment and 11 months after ADT completion with return of normal testosterone levels.

\section{Discussion}

In the last two decades, with the introduction and popularization of PSA screening, the detection of low-grade localized prostate cancer has dramatically increased. This has led to the development of a number of alternative treatments for patients who are not surgical candidates due to age or comorbidities. Research and development of HIFU began in the 1950s with its first use as a prostate cancer treatment in the 1990s. It has become an alternative treatment for low- or intermediate-risk prostate cancer in men over the age of 70 with a prostate volume less than 40 grams. ${ }^{2-4}$

HIFU is a non-invasive, day procedure resulting in less erectile dysfunction and incontinence than a prostatectomy. ${ }^{5,6}$ Additionally, unlike ionizing radiation, HIFU has no lifetime dose limit and does not increase the risk of secondary malignancies later in life. HIFU involves non-ionizing, acoustic radiation (ultrasound waves) absorbed by prostate tissue which causes heating over 2 to 3 seconds to a temperature between $80^{\circ} \mathrm{C}$ and $100{ }^{\circ} \mathrm{C}$ resulting in tissue cavitation. The tissue is then cooled and the cycle is repeated. ${ }^{7}$ 
The focused energy causes coagulative necrosis, cell disruption and apoptosis. The ultrasound waves are released by a transrectal transducer causing minimal damage to adjacent tissues. ${ }^{8}$ In addition to being used to treat prostate cancer, HIFU is also an emerging treatment option for other easily accessible tumours, including breast, liver, kidney and primary bone tumours. ${ }^{9}$

Currently in Canada, $90 \%$ of HIFU is used as primary therapy, while only $10 \%$ is salvage treatment. ${ }^{10}$ Salvage radiation is the primary salvage treatment modality used for biochemical failure after RP. However the question remains of what to do with patients with biochemical failure after prostatectomy and EBRT. Traditionally these patients would be treated with ADT which delays metastasis but has no potential to cure disease. HIFU has been used as salvage therapy following biochemical failure after primary EBRT with good results in a number of studies. ${ }^{11,12}$ More recently, HIFU has been used as salvage treatment for local prostate cancer recurrence after RP. Murota-Kawano and colleagues reported on 4 patients with biopsy-confirmed recurrence with biochemical failure after RP, of which 3 patients received salvage EBRT. At 24 months, 2 of the 4 patients were biochemically disease-free. ${ }^{13}$ Asimakopoulos and colleagues reported on 19 patients who underwent salvage HIFU with biochemical recurrence after RP. They reported a 10.5\% immediate failure rate, and of the remaining 17 patients an additional $47 \%$ failure rate with a median follow-up of 48 months. It was determined that those with lower Gleason scores and lower PSA values had a better outcome than those patients with higher Gleason scores and higher PSA values. ${ }^{14}$ Although these two studies provide promise for salvage HIFU after $\mathrm{RP}$, further research and additional follow-up are required to better evaluate this salvage therapy.

With an increasing number of men diagnosed and receiving prostate cancer treatment earlier in life, biochemical failure and salvage therapy are becoming more common. Biochemical recurrence-free survival ranges from $47 \%$ to $72 \%$ at the 10 -year follow-up with biochemical failure requiring further treatment. ${ }^{15,16} \mathrm{HIFU}$ may become an important salvage therapeutic option because it is non-ionizing, minimally invasive, and has the potential for a curative outcome. $^{7}$

\section{Conclusion}

HIFU is predominantly used as a primary treatment or as salvage treatment after EBRT. We presented a case and brief literature review of salvage HIFU used after RP and failed EBRT. Due to the low morbidity of HIFU and the promising early results from two small studies, HIFU may be considered a viable treatment option as a salvage modality for the rare occasion of biopsy-confirmed disease recurrence after RP and failed EBRT.
Competing interests: Dr. Rittberg and Dr. Kroczak declare no competing financial or personal interests. Dr. Fleshner is a member of the advisory boards for Amgen, Janssen, Astellas and Eli Lily. He has received honoraria from Amgen, Janssen, Astellas, and Eli Lily. He is and has participated in clinical trials for Amgen, Janssen, Medivation, OICR, and Prostate Cancer Canada. Dr. Drachenberg has attended Advisory Boards for Astellas and Janssen and has been a speaker for Amgen and Actavis (formerly Watson). He has also been an investigator in clinical trials run by Cancer Care Manitoba (CCMB)

This paper has been peer-reviewed.

\section{References}

1. Ellison LF, Wikins K. Canadian population cancer prevalence in the Canadian population. Health Rep 2009;20:7-19.

2. Cordeiro ER, Cathelineau $X$, Thüroff $S$, et al. High-intensity focused ultrasound (HIFU) for definitive treatment of prostate cancer. BJU Int 2012;110:1228-42. http://dx.doi.org/10.1111/i.1464410X.2012.11262.x

3. Blana A, Murat FJ, Walter $B$, et al. First analysis of the long-term results with transrectal HIFU in patients with localised prostate cancer. Eur Urol 2008;53:1194-1203. http://dx.doi.org/10.1016/i. eururo.2007.10.062

4. Rebillard X, Soulié M, Chartier-Kastler E, et al. High-intensity focused ultrasound in prostate cancer: A systematic literature review of the French Association of Urology. BJU Int 2008;101:1205-13. http:// dx.doi.org/10.1111/i.1464-410X.2008.07504.x

5. Crouzet $S$, Rouviere 0 , Martin $X$, et al. High-intensity focused ultrasound as focal therapy of prostate cancer. Curr Opin Urol 2014;24:225-30. http://dx.doi.org/10.1097/MOU.0000000000000053

6. Shoii S, Nakano M, Nagata Y, et al. Quality of life following high-intensity focused ultrasound for the treatment of localized prostate cancer: A prospective study. Int J Urol 2010;17:715-9. http://dx.doi. org/10.1111/i.1442-2042.2010.02568.x

7. Barkin J. High intensity focused ultrasound (HIFU). Can J Urol 2011;18:5634-43.

8. Rove KO, Sullivan KF, Crawford ED. High-intensity focused ultrasound: Ready for primetime. Urol Clin North Am 2010;37:27-35. http://dx.doi.org/10.1016/i.ucl.2009.11.010

9. Tempany CM, Mcdannold NJ, Hynynen K, et al. Focused ultrasound surgery in oncology: Overview and principles. Radiology 2011;259:39-56. http://dx.doi.org/10.1148/radiol.11100155

10. Lukka H, Waldron T, Chin J, et al. High-intensity focused ultrasound for prostate cancer: A practice guideline. Can Urol Assoc J 2010;4:232-6.

11. Gelet A, Chapelon JY, Poissonnier L, et al. Local recurrence of prostate cancer after external beam radiotherapy: Early experience of salvage therapy using high-intensity focused ultrasonography. Urology 2004;63:625-9. http://dx.doi.org/10.1016/j.urology.2004.01.002

12. Murat F-J, Poissonnier L, Rabilloud M, et al. Mid-term results demonstrate salvage high-intensity focused ultrasound (HIFU) as an effective and acceptably morbid salvage treatment option for locally radiorecurrent prostate cancer. Eur Urol 2009;55:640-7. http://dx.doi.org/10.1016/i.eururo.2008.04.091

13. Murota-Kawano A, Nakano M, Hongo $S$, et al. Salvage high-intensity focused ultrasound for biopsyconfirmed local recurrence of prostate cancer after radical prostatectomy. BJU Int 2009;105:1642-5. http://dx.doi.org/10.1111/i.1464-410X.2009.08990.x

14. Asimakopoulos AD, Miano R, Virgili $G$, et al. HIFU as salvage first-line treatment for palpable, TRUSevidenced, biopsy-proven locally recurrent prostate cancer after radical prostatectomy: A pilot study. Urol Oncol 2012;30:577-83. http://dx.doi.org/10.1016/j.urolonc.2010.08.019

15. Trapasso J, DeKernion J, Smith R, et al. The incidence and significance of detectable levels of serum prostate specific antigen after radical prostatectomy. J Urol 1994;152:1821-5.

16. Han $M$, Partin AW, Zahurak $M$, et al. Biochemical (prostate specific antigen) recurrence probability following radical prostatectomy for clinically localized prostate cancer. J Urol 2003;169:517-23. http://dx.doi. org/10.1016/S0022-5347(05)63946-8

Correspondence: Dr. Tadeusz Kroczak, Section of Urology, Department of Surgery, University of Manitoba, Winnipeg, MB; umkroczo@cc.umanitoba.ca 